Received: 11.10 .2019

Revised: 15.10 .2019

Accepted: 20.12 .2019

DOI: $10.17804 / 2410-9908.2019 .6 .015-025$

\title{
APPLICABILITY OF MAGNETIC TRANSDUCERS TO MEASURING STRAINS AND EVALUATING THE SERVICE LIFE OF STRUCTURAL COMPONENTS
}

\author{
V. F. Novikov ${ }^{\text {a) }}$, K. P. Muratov ${ }^{\text {b) }}$, and S. M. Kulak ${ }^{\text {c)* }}$ \\ Tyumen Industrial University, \\ 38 Volodarskogo St., Tyumen, 625000, Russian Federation \\ a) (iD https://orcid.org/0000-0002-1987-351X \\ b) (iD https://orcid.org/0000-0002-8079-2022 \\ c) (iD https://orcid.org/0000-0002-5970-8893 ksm-rabochi@rambler.ru \\ *Corresponding author. E-mail: ksm-rabochi@rambler.ru \\ Address for correspondence: ul. Melnikaite, 70, Tyumen, 625039, Russian Federation
}

Magnetoelastic demagnetization of wires and foils made of ferromagnetic materials is studied during cyclic mechanical tests. The behavior of the magnetic properties of the $30 \mathrm{Kh} 13$ and 30K4MVI steels allowing their use in foil or wire design as magnetic transducers of strains in structures and structural components is revealed. Sensors of this type can be more highly sensitive than tensoresistive ones, they are wireless, less time-consuming to install, and more cost-effective.

Keywords: strain gauge, fatigue of structures, magnetoelastic demagnetization, cyclic loads.

\section{References}

1. Terent'ev V.F. and Korableva S.A. Ustalost metallov [Fatigue of Metals]. Moscow, Nauka Publ, 2015, 479p.

2. Nesterenko B.G. Development of regulatory requirements for fatigue and survivability of civilian transport aircraft. Problemy mashinostroeniya i nadyozhnosti mashin, 2010, no. 6, pp.117-126. DOI: 10.3103/S1052618810060154. (In Russian).

3. Panin S.V., Burkov M.V., Lyubutin P.S., Altukhov Yu.A., Khizhnyak S.A. Application of integral-type deformation pickups for evaluating the fatigue damage of carbon composites Rossijskij zhurnal nerazrushayushchego kontrolya, 2014, Vol. 50, no. 5,pp. 288-298. (In Russian).

4. Syzrantsev V.N. and Golofast S.L. Izmerenie tsiklicheskikh deformatsiy i prognozirovanie dolgovechnosti detaley po pokazaniyam datchikov deformatsii integralnogo tipa [Measurement of Cyclic Deformation and Prediction of Component Life from Deformation Sensor Readings of an Integral Type]. Novosibirsk, Nauka Publ., 2004. (In Russian).

5. Kopnov V.A., Kotelnikov A.P. Forecasting of metal structures resource on transport machines by stress sensors of integral type. Izvestiya Vysshykh Uchebnykh Zavedeniy. Gornyy Zhurnal, 2009, no. 3, pp. 76-82. (In Russian).

6. Kotelnikov A.P. How to use film deformation pickups of integral type in mode of deformation diagnostic of transport fabricated metals. Transport Urala, 2006, no. 3 (10), pp. 57-61. (In Russian).

7. Titorenko K.V., Dudko A.V. The study of metal fatigue with the use of strain gauges. In: Nauchnyi poisk, Teoriya i praktika, Almanakh: sbornik. Ufa, 2017, pp. 66-69. (In Russian).

8. Popov B.E., Bezlyud'ko G.Ya., Elkina E.I., and Solomakha R.N., Metal fatigue testing by the coercimetric method as an objective primary basis for the diagnostics of equipment and structures. V Mire NK, 2009, no. 2 (44), pp. 28-32. (In Russian). 
9. Dmitriev V.F. Wireless surface acoustic wave deformation sensor. Voprosy Radioelektroniki, 2012, vol. 2, no. 1, pp. 153-162. (In Russian).

10. Fedortsev R.V., Rogozhinsky E.Yu., Barkin K.V., Cherenko D.V. Research of value of deformation, stress and self frequency oscillation of the star sensor with equivalent inertial weighting. Devices and Methods of Measurements, 2011, no. 2, pp. 92-98. (In Russian).

11. Barannikov V.A., Nikolaeva E.A., Kasatkina S.N. Simple electromagnetic sensor of instantaneous deformations. Zavodskaya Laboratoriya. Diagnostika Materialov, 2007, vol. 73, no. 3, pp. 66-68. (In Russian).

12. Novikov V.F. and Bakharev M.S. Magnitnaya diagnostika mekhanicheskikh napryazheniy v ferromagnetikakh [Magnetic Diagnostics of Mechanical Stresses in Ferromagnets]. Tyumen, Vektor Buk Publ., 2001. (In Russian).

13. Novikov V.F., Neradovsky D.F., Fedorov B.V., Strokova A.V. Magnetoelastic phenomena in residually magnetized cobalt steel. Russian Journal of Nondestructive Testing, 2017, vol. 53, iss. 3, pp 198-203. DOI: 10.1134/S1061830917030068.

14. Novikov V.F., Muratov K.R., Paderin K.S., Bakharev M.S., Rogaleva E.V. Band-cordless deformation sensor. Datchiki $i$ sistemy, 2011, no. 9, pp. 47-49. (In Russian).

15. Novikov V.F., Yatsenko T.A., and Bakharev M.S., Izv. Vyssh. Uchebn. Zaved. Neft' i Gaz, 1998, no. 4, pp. 92-102. (In Russian).

16. Novikov V.F., Drozdov N.A., Kulak S.M., Muratov K.R., Neradovskii D.F. Electromagnetic Witness Transducers of Pre-Fracture of Structures. Russian Journal of Nondestructive Testing, 2019, vol. 55, no. 8, pp. 603-609. - DOI: 10.1134/S1061830919080096.

17. Drozdov N.A. Electromagnetic converters - witnesses of structural failure. In: Novye tekhnologii - neftegazovomu rayonu. Mater. Vseros. s mezhdunar. uchastiem nauchno-prakt. konf. studentov, aspirantov i molodykh uchenykh [New Technologies for the Oil and Gas Region. Proc. All-Russ. with int. participation sci.-pract. conf. stud. grad. stud. young sci.]. 2015, pp. 154-157. (In Russian).

18. Fedosenko Yu.K., Shkatov P.N., and Efimov A.G. Vikhretokovyi kontrol' [Eddy Current Testing]. Moscow, Spektr Publ., 2011. 
Подана в журнал: 11.10 .2019

УДК 620.179.14:620.178.3

DOI: $10.17804 / 2410-9908.2019 .6 .015-025$

\title{
ВОЗМОЖНОСТИ МАГНИТНЫХ ПРЕОБРАЗОВАТЕЛЕЙ ДЛЯ ИЗМЕРЕНИЯ ДЕФОРМАЦИИ И ОЦЕНКИ ЭКСПЛУАТАЦИОННОГО РЕСУРСА ЭЛЕМЕНТОВ КОНСТРУКЦИИ
}

\author{
В. Ф. Новиков ${ }^{\text {a) }}$, К. Р. Муратов ${ }^{\text {б) }}$, С. М. Кулак ${ }^{\text {в)* }}$ \\ ФГБОУ Тюменский индустриальный университет, \\ 38, ул. Володарского, г. Тюмень, Российская Федераџия \\ a) (iD https://orcid.org/0000-0002-1987-351X \\ б) (iD https://orcid.org/0000-0002-8079-2022 \\ в) (iD https://orcid.org/0000-0002-5970-8893 $\otimes$ ksm-rabochi@ rambler.ru \\ *Ответственный автор. Электронная почта: ksm-rabochi@ rambler.ru \\ Адрес для переписки: г. Тюмень, ул. Мельникайте, 70, Российская Федерация
}

Исследовано магнитоупругое размагничивание проволок и фольг из ферромагнитных материалов в ходе циклических механических испытаний. Установлены закономерности изменения магнитных свойств, сталей 30Х13, 30К4МВИ позволяющие их использование в фольговом или проволочном исполнении в качестве магнитных преобразователей деформации конструкций и их элементов. Такой тип датчиков может быть высокочувствительным по сравнению с тенорезистивными, беспроводным, менее трудоемким в монтаже и более экономически выгодным.

Ключевые слова: датчик деформации, усталость конструкций, магнитоупругое размагничивание, циклические нагрузки.

\section{1. Введение}

Определение эксплуатационного ресурса трубопроводов, мостов, машин, самолетов с высокой достоверностью имеет большое экономическое значение. Недооценка ресурса уменьшает эксплуатационный срок изделия и соответственно уменьшает его самоокупаемость. Переоценка ресурса чревата авариями и гибелью людей. В мире идет поиск методов информационных параметров для определения предельного ресурса, разрабатываются серьезные математические методы его подсчета. Но без достоверной первичной информации вероятностный подход страдает существенной неопределенностью, требует для безопасной эксплуатации большой запас прочности, что существенно удорожает продукцию. Необходим поиск параметров состояния материала, используемого для контроля усталостных изменений элементов конструкции в процессе их эксплуатации [1-2]. В работах [3-6] предложен метод определения усталостного ресурса с помощью датчиков деформации интегрального типа. Они представляют собой немагнитную фольгу (алюминий, медь, олово, индий), наклеенную на испытуемый образец. В процессе наработки в ней накапливаются дефекты, и фольга начинает темнеть. Информация с датчиков считывается оптическим методом с помощью микроскопа и косвенно оценивается степень наработки элемента конструкции.

Определение деформации элементов конструкций можно осуществлять с помощью наклеиваемых на них электрических тензодатчиков [7]. При этом надежность использования тензодатчиков и точность их показаний обусловлена качеством приклейки, процедура которой зачастую является трудоемкой, и не осуществимой в условиях низких температур. Такие датчики нуждаются в соединительных проводах, которые иногда трудно совместимы 
с динамичностью конструкции. Поэтому актуальным является вопрос создания перспективно новых датчиков деформации, которые могут обходиться без соединительных проводов [9], обладать элементом памяти, а съем информации можно осуществлять дистанционно с помощью датчиков магнитного поля [8]. Для таких случаев полезным могли бы быть преобразователи (датчики) в виде фольги или проволоки из магнитных материалов сплавов. Физической основой работы преобразования деформации в электрический сигнал являются необратимый или квазиобратимый магнитоупругие явления наблюдаемые в ферромагнитных материалах $[12,13]$. Магнитоупругое размагничивание ферромагнетика (МУР) заключается в необратимом изменении его остаточной намагниченности (М) при приложении механических напряжений у (так называемая магнитоупругая «память»). Квазиобратимое магнитоупругое явление (пьезомагнитный эффект остаточно намагниченного состояния (ПМЭ)) заключаются в следующем: у некоторых ферромагнитных сплавов после их намагничивания и приложения многократных нагрузок в упругой области остаточная намагниченность М не исчезает. А последующие нагружения сопровождаются установившимся квазиобратимым изменением намагниченности (и соответственно ее магнитным полем рассеяния).

\section{2. Материалы и методика исследований}

Цель работы - исследование необратимых и квазиобратимых изменений магнитного поля рассеяния (намагниченности) проволочного и фольговых образцов, находящихся в остаточно намагниченном состоянии под действием циклически создаваемых напряжений. Для изготовления образцов в виде фольги размерами $(0,1 \times 15 \times 15)$ мм и проволоки диаметром $\mathrm{d}=1$ мм, длиной до $1=100$ мм использовались высоколегированная сталь $30 \mathrm{X} 13$ и сталь 30К4МВИ. Затем они подвергались термической обработке в режиме (отжиг в диапазоне от 200-700 ${ }^{\circ} \mathrm{C}$ ), обеспечивающем оптимальные свойства: чувствительность, гистерезис, вязкость и др. Для запоминающего датчика, и для датчика, предназначенного для работы в режиме on-line это, как правило, разные режимы.

Готовые проволочные образцы крепились на пластины из немагнитного материала с помощью винтов и сварки, а фольги приклеивались, после чего производилось их намагничивание электромагнитом или постоянным магнитом до насыщения.

Измерение магнитного поля рассеяния образцов осуществлялось с помощью феррозондовых магнитометров МЦ-3.003, и МФ 205. Пластины с размещенными (закрепленными) на них проволочными и фольговыми образцами циклически нагружались растяжением в машине ИР 5047-50 со скоростью $\mathrm{v}=$ 0,1 мм/мин в упругой области их деформаций. При первом после намагничивания цикле нагружения пластин с исследуемыми проволочными и фольговыми образцами определялось необратимое изменение остаточной намагниченности $(\Delta \mathrm{M})$ по убыли соответствующей ей напряженности магнитного поля рассеяния $\Delta \mathrm{H}$ (магнитоупругая «память»), а после многократного (до 20 циклов) нагружения (растяжения) записывалось квазиобратимое изменение намагниченности образцов.

C помощью компьютерных программ «Испытание металла» и «DigMag3» регистрировались приложенное к пластинам с образцами растягивающие усилия $\mathrm{F}$, создающие в их поперечном сечении $\mathrm{S}$ напряжения растяжения $\sigma$ и соответствующая им величина магнитного поля рассеяния Н остаточно намагниченных проволок и фольг и графически устанавливалась зависимость $\mathrm{H}=\mathrm{f}(\sigma)$.

\section{3. Результаты и их обсуждение}

Деформационное размагничивание образца (необратимая убыль величины магнитного поля рассеяния) представлено на рис. 1. Остаточная намагниченность материала, рассчитанная по напряженности магнитного поля рассеяния $\mathrm{H}$, монотонно (практически линейно) убывает с ростом величины однократно прикладываемого механического напря- 
жения у после его снятия. Как видно, материал проволочного датчика способен «запомнить» величину пиковых напряжений в диапазоне 0-500 МПа.

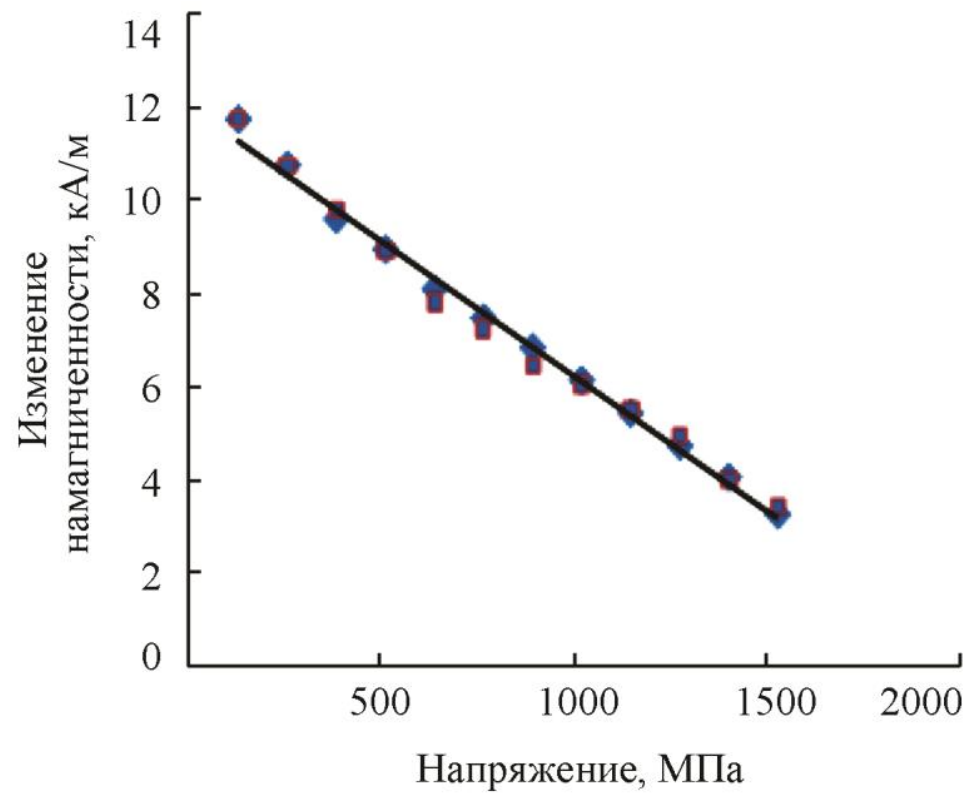

Рис. 1. Зависимость изменения остаточной намагниченности $\Delta \mathrm{M}$ (кА/м) двух термообработанных ( и ш) проволочных образцов из стали 30К4МВИ от напряжения растяжении $\sigma$ (МПа) при первом цикле нагружения-разгружения

Чувствительность испытуемых образцов к напряжениям из фольги зависит от направления их намагничивания. Она больше, если образец намагничивается в направлении перпендикулярном к последующей деформации. Как следует из рис. 2 величина изменения напряженности магнитного поля рассеяния фольгового образца при ортогональной ориентации напряжений к направлению намагниченности составляет $\sim 315 \mathrm{~A} / \mathrm{M}$, а при соосной 200 $\mathrm{A} / \mathrm{M}$.

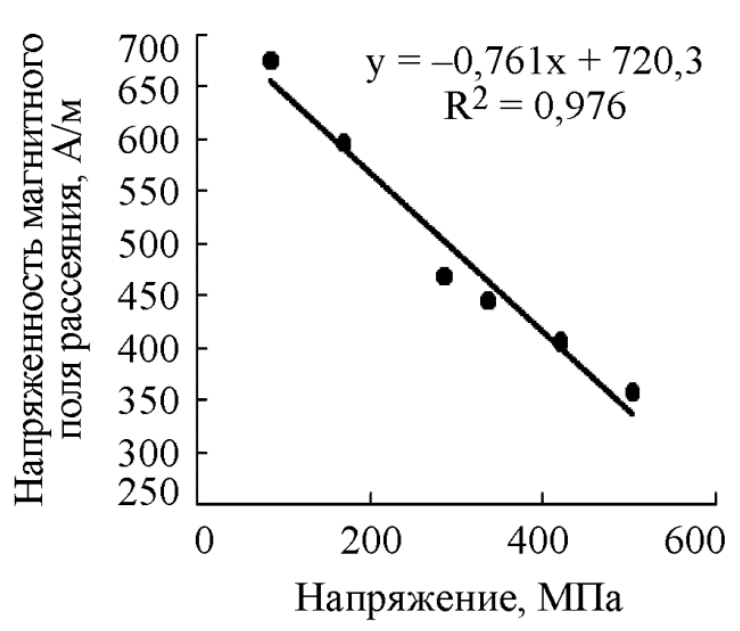

$a$

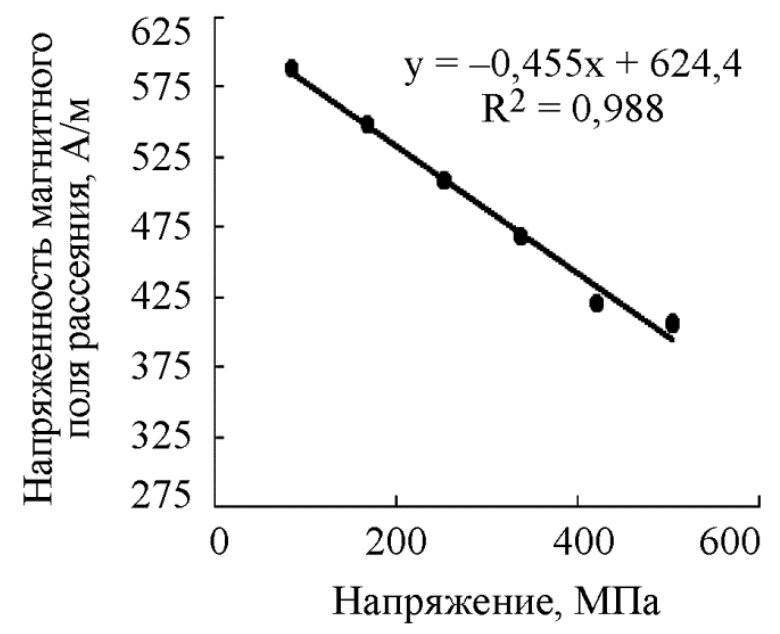

6

Рис. 2. Магнитоупругое размагничивание фольгового образца в виде диска из стали 30Х13: $a$ - вектор силы F (напряжения) ортогонален к направлению остаточной намагниченности М; $\sigma$ - соосное расположение векторов остаточной намагниченности М и создаваемого напряжения 
Особенностью МУР является и то, что величина поля рассеяния практически не меняется, если последующие нагрузки будут меньше предыдущей. В результате материал преобразователя (в виде проволоки или фольги) запомнит величину максимального (пикового) напряжения. На рис. 3 а показано, изменение магнитного поля рассеяния при нагружении разгружении возрастающей нагрузкой образца изготовленного из стали 30X13 (фольга). На рис 3 б показано изменение напряженности Н магнитного поля рассеяния при 4х-кратном нагружении до максимальной величины у того же образца. Видно, что полупетля зависимости $\mathrm{H}=\mathrm{f}(\sigma)$ (рис. 3 б) является, по-существу, огибающей для частных полупетель (рис. $3 a$ ) в рассматриваемом диапазоне нагрузок.

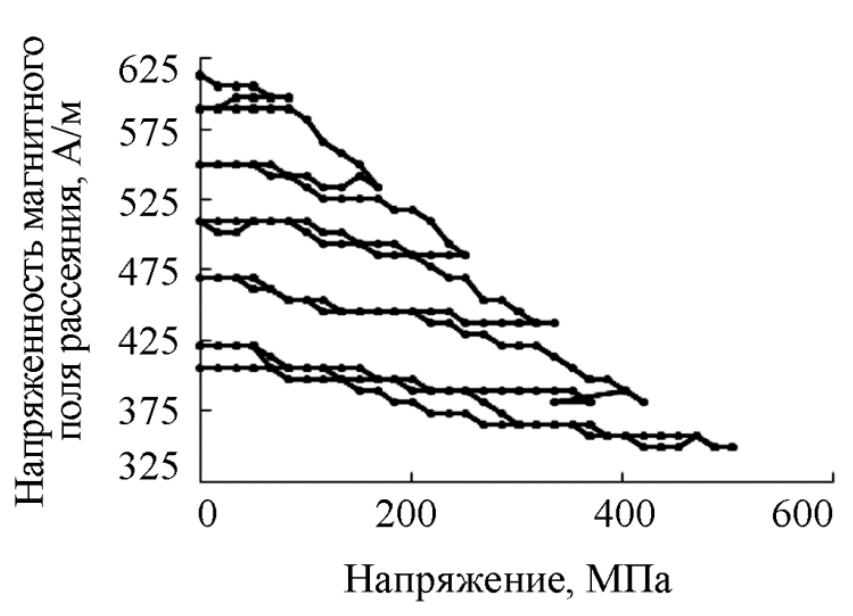

$a$
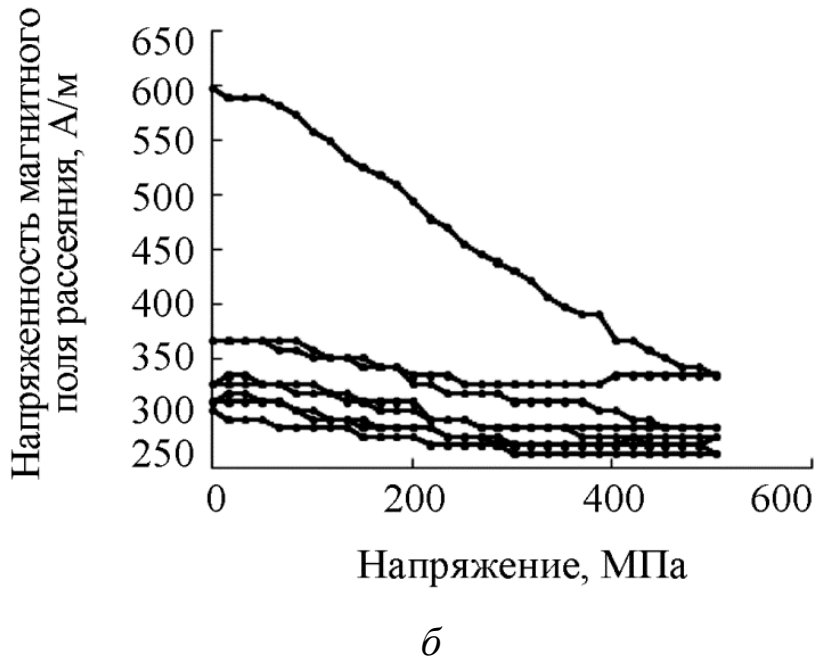

Рис. 3. Изменение напряженности магнитного поля рассеяния остаточно намагниченной фольги при его шестикратном (a) нарастающем нагружении-разгружении и четырехкратном

(б) нагружении до максимального значения напряжений $500 \mathrm{MПа}$

Природа необратимого МУР [12, 13] заключается в следующем. В доменной структуре остаточно намагниченного ферромагнетика объем магнитных фаз с намагниченностью, ориентированной по полю превосходит объемы фаз, ориентированных против поля. Сформировавшаяся доменная структура является метастабильной, поскольку удерживается дефектами решетки, включениями, границами зерен, градиентами механических напряжений. В результате ферромагнетик будет иметь остаточную намагниченность тем большую, чем больше существует факторов, мешающих движению междоменных границ. Остаточная намагниченность порождает внутри магнетика размагничивающее поле, зависящее от внутреннего и внешнего размагничивающего фактора, который определяется формой образца и дисперсностью структуры материала.

При создании в образце механических напряжений в результате изменения магнитоупругой энергии ферромагнетика 90- или 109-градусные доменные границы придут в движение. Например, при сжатии материала с константой магнитострикции $\lambda_{100}>0$ магнитоупругое взаимодействие стремится выстроить векторы намагниченности в направлении, перпендикулярном оси действия напряжений. Доменные границы в этом случае, если не слишком велико их сцепление с дефектами кристаллической решетки, будут преодолевать энергетические барьеры и выходить из метастабильного состояния. В результате действия размагничивающего поля образца, обусловленного его формой, дисперсной кристаллической структурой, внутренними «магнитными зарядами» и механическими напряжениями, междоменные границы будут двигаться так, чтобы уменьшить магнитостатическую энергию взаимодействия намагниченности с внутренним магнитным полем и занимать новые метастабильные состояния с новым минимумом всех энергий. Последующее нагружение до тех же величин 
напряжений уже не приводит к таким изменениям в доменной структуре, как это было при первом нагружении, так как основная масса энергетических барьеров на пути перестройки магнитной структуры уже была преодолена. Если же нагрузку снова увеличить, то будут преодолены новые энергетические барьеры и произойдет новое необратимое изменение намагниченности.

Характер квазиобратимого изменения магнитного поля рассеяния намагниченного и подвергнутого многократным упругим деформациям чувствительного элемента (тренировка) при нагружении и снятии нагрузки ПМР [15] показан на рис. 4. Из рисунка следует, что с увеличением прикладываемых напряжений (в пределах используемой для тренировки деформации) величина поля монотонно растет. При снятии напряжения величина поля следует практически по той же кривой. Отсутствие гистерезиса говорит об однозначности показаний измерительной системы. Процессы намагничивания в этом случае осуществляются когерентным вращением. С этим связано увеличение коэрцитивной силы [13]. И пока увеличение-снятие поля не превышает значение критической нагрузки, такого рода изменения намагниченности являются безгистерезисными. При приложении напряжений магнитоупругое взаимодействие должно приводить к когерентному повороту векторов намагниченности в направлении приложения нагрузки и связанное с этим увеличение намагниченности. Снятие нагрузки сопровождается возвращением векторов намагниченности в исходное положение. Этим и объясняется безгистерезисный характер пьезоэффекта. Наличие такого эффекта наблюдаемого в (сталях 30К4МВИ, 30Х13 и др.) свидетельствует об определенной кристаллографической структуре материала и позволяет создавать из него сенсоры деформации и напряжения $[13,15]$. Сочетание высокой прочности сплава и чувствительности к упругим напряжениям могут позволить использовать его при создании датчиков силы и деформации и изготовлении чувствительных элементов в робототехнике.

Преобразователи на основе МУР $[16,17]$ целесообразно использовать тогда, когда необходимо зафиксировать максимальную величину деформации не отслеживая ее изменения во времени приборными средствами, так как чувствительный элемент сам запоминает максимальную величину деформации, которая имела место в промежутке между намагничиванием - первым измерением и измерением после исследуемого силового воздействия.

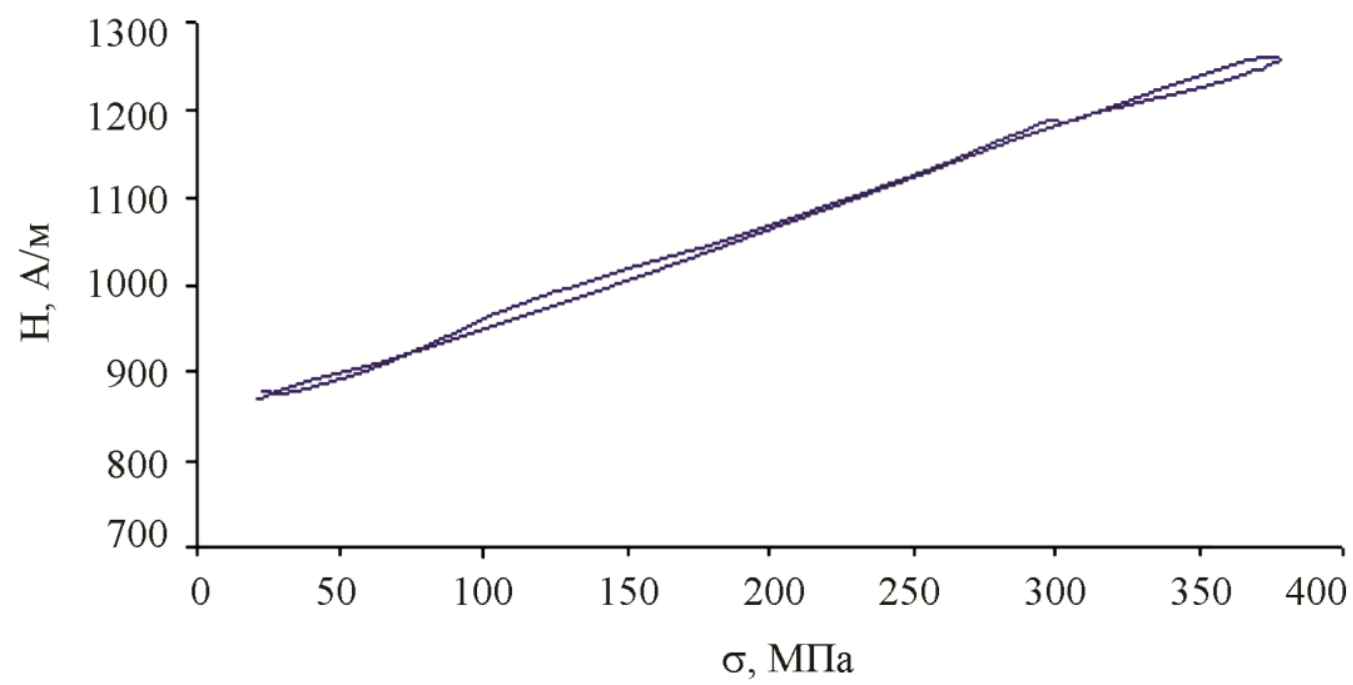

Рис. 4. Изменение напряженности магнитного поля рассеяния отожженного при $600{ }^{\circ} \mathrm{C}$ остаточно намагниченного образца стали 30К4МВИ от величины напряжения растяжения после тренировки (десятикратного циклирования при максимальном усилии 242H). Режим пьезомагнитного эффекта 
Преобразователи, работающие в режиме ПМЭ [14,15], могут быть использованы для измерения деформации (силы) в режиме on-line.

Для исключения влияния внешнего магнитного поля на результаты определения величины деформации целесообразно преобразователи делать парными. При этом один преобразователь намагничивать в одном направлении, другой - противоположном. Изменение температуры в сторону низких значений практически не сказывается на результатах измерений. Высокие температуры работы до $300{ }^{\circ} \mathrm{C}$ приводят к небольшим до 5-7 \% изменениям выходного сигнала.

Дешевизна преобразователей позволит снабдить исследуемую конструкцию большим числом датчиков, и получить полную картину максимальных деформаций, испытываемых конструкцией в процессе ее эксплуатации. Их можно использовать для контроля деформации элементов (в том числе и в режиме запоминания) при транспортировке ракет, прецизионного оборудования, станков, оптических приборов и др.

В работах $[16,17]$ предложено использовать наклеиваемые ферромагнитные фольги в качестве преобразователей усталостных изменений в элементах конструкций из немагнитных материалов, отслеживаемых вихретоковым прибором. При таком подходе может быть увеличена чувствительность метода контроля, так как кроме электрической привлекается еще и магнитная характеристика материала фольги. На испытуемый образец наклеивалась ферромагнитная фольга - преобразователь усталости материала. Усталость в датчике должна проявляться так же, как и в исследуемом объекте, т. е. в нем в процессе наработки увеличится плотность дислокаций, возникнут микротрещины, которые увеличивают удельное электросопротивление и уменьшают магнитную проницаемость, что сказывается на изменении сигнала вихретокового дефектоскопа[18].

В ходе эксперимента в качестве преобразователей усталости использовались фольги прямоугольной формы из никеля, а также сплавов железа и никеля, размерами $23 \times 15 \times 0,02$ (мм) и $19 \times 13 \times 0,01$ (мм) как в деформированном, так и отожженном в вакууме при $1000{ }^{\circ} \mathrm{C}$ состоянии. В качестве испытуемого образца использовалась титановая пластина, размерами $143 \times 28 \times 0,8$ (мм). Пластина консольно закреплялась на вибростенде и подвергалась многоцикловому динамическому нагружению. Датчики приклеивались к образцу клеем БФ-2, в местах соответствующим максимальным значениям напряжений сжатия и растяжения, вблизи закрепленной части пластины. Частота колебаний испытуемой пластины задавалась в пределах от 50-100 Гц. Динамическое нагружение образцов проводилось до их полного излома.

Через каждые 300 циклов нагружения образцов с помощью вихревого дефектоскопа «Вектор» выполнялись измерения безразмерного комплексного параметра $\widehat{\mathrm{Z}}=X+i \cdot Y$, характеризующего электромагнитные свойства пленки. Вещественные и мнимые составляющие этого параметра зависят от проводимости материала пленки и ее магнитной проницаемости.

На рис. 5 приведены результаты измерения мнимой компоненты Y безразмерного параметра Z в трех точках железоникелевой фольги, в зависимости от числа циклов ее нагружения. Как видно на протяжении порядка 260 килоциклов нагружения пластины с наклеенной пермаллоевой фольгой, показания вихретокового прибора неизменны, и лишь с началом их усталостного разрушения наблюдается резкий рост мнимой компоненты Ү. Такие изменения сигнала вихретокового прибора вызваны убылью магнитной проницаемости и ростом электросопротивления фольги в процессе усталостных изменений в ней и пластине - подложке. 


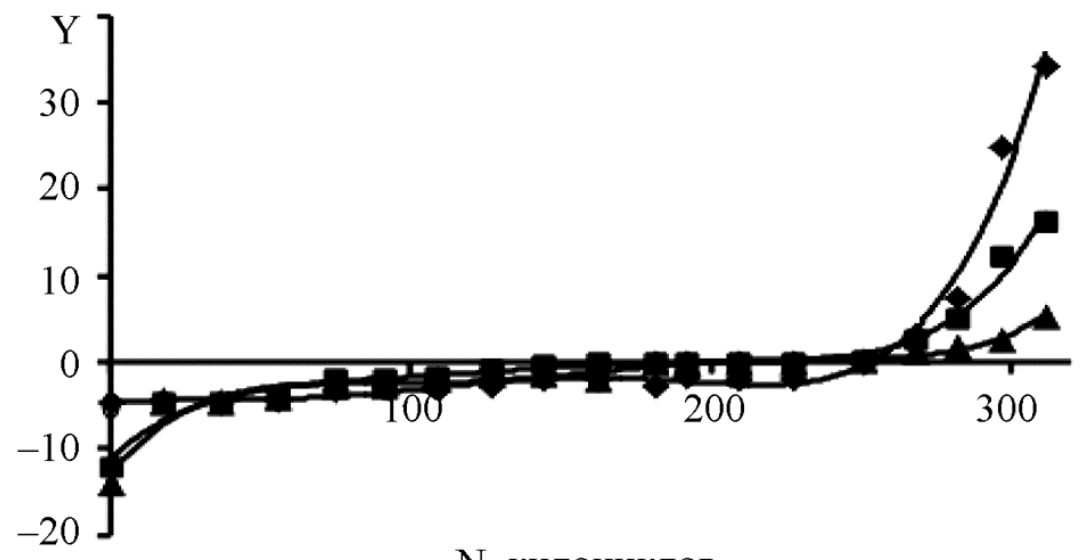

\section{$\mathrm{N}$, килоциклов}

Рис. 5. Зависимость мнимой компоненты Y безразмерного параметра $\mathrm{Z}$ сигнала вихретокового прибора в трех точках не отожженной (наклепанной) пермаллоевой фольги толщиной 20 мкм от числа килоциклов $\mathrm{N}$ ее нагружения до разрушения: $\mathbf{a}$ - точка в центре фольгового элемента; - точка на краю фольги, ближе к месту крепления; $\boldsymbol{\Delta}$ - точка на краю фольги наиболее удаленная от места крепления пластины.

Рис. 5 показывает, что предлагаемый вид преобразователя в виде наклеиваемой фольги из никеля и его сплавов способен регистрировать предразрушение испытываемого элемента конструкции.

Показания вихретокового преобразователя относительны, требуют настройки вихретокового прибора перед измерениями. Поэтому была поставлена задача изготовления прибора, который позволял бы отслеживать усталостные изменения фольги. Был изготовлен Побразный индукционный преобразователь, который вместе с исследуемой фольгой представлял датчик-свидетель усталостных изменений в нагружаемой пластине. В качестве вторичного прибора служил автогенератор RLC типа $[16,17]$ рис. 6.

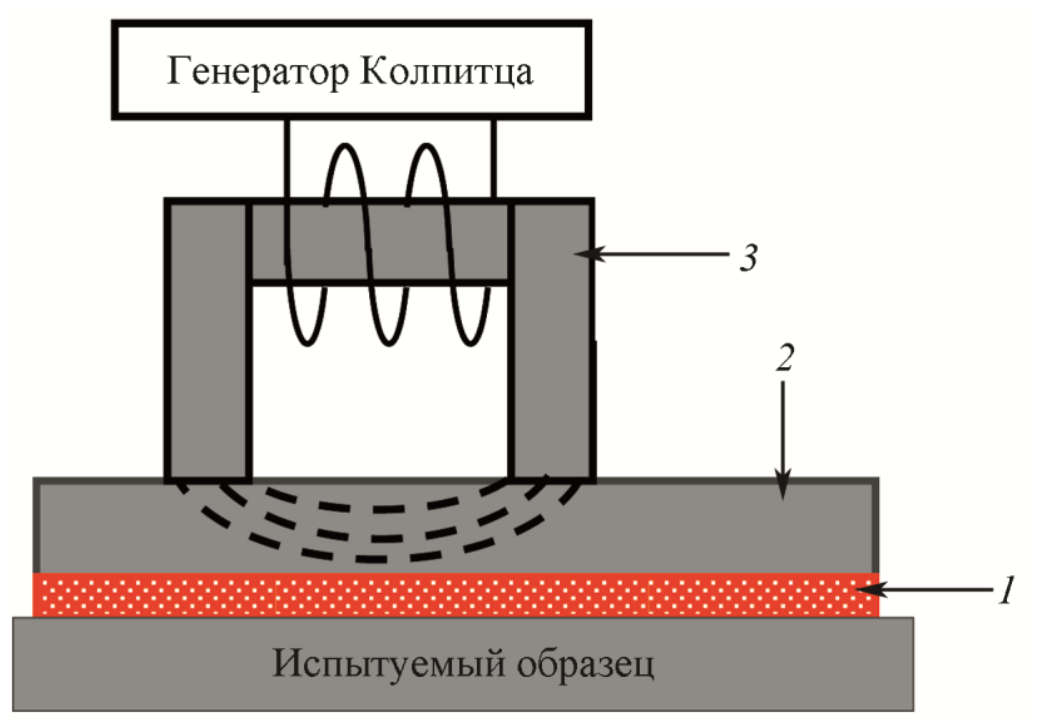

Рис. 6. Схема преобразователя электромагнитных параметров фольг: 1 - слой клея; 2 - электромагнитный преобразователь (фольга); 3 - П-образный электромагнит 


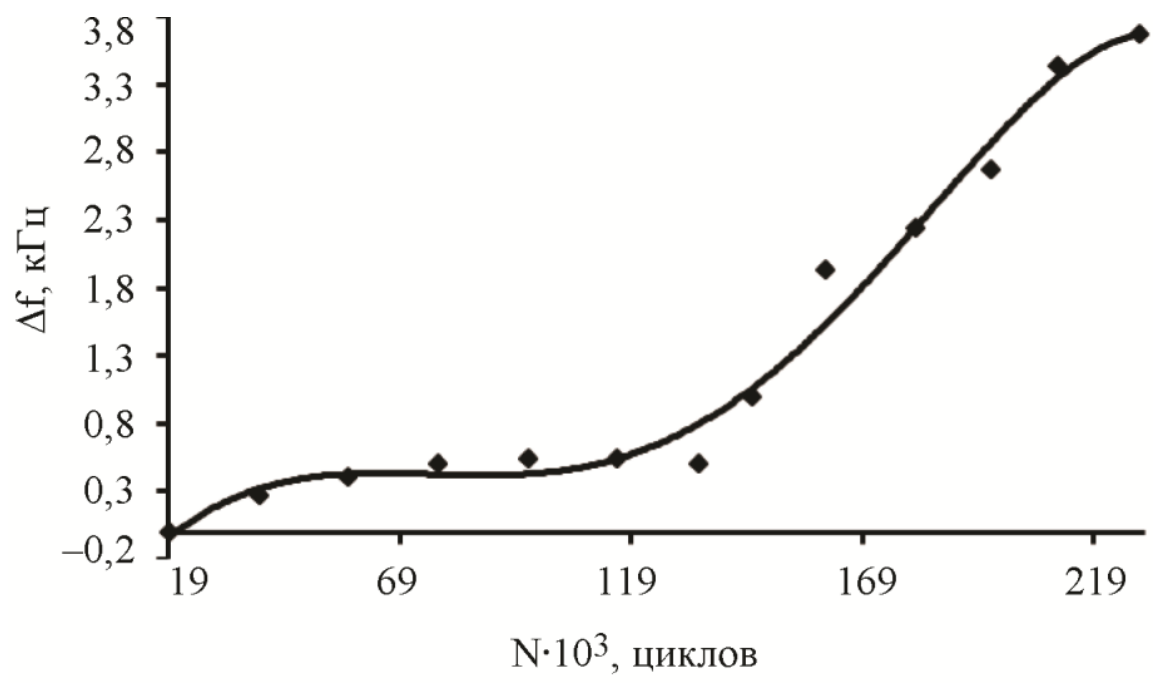

Рис. 7. Зависимость приращения частоты сигнала электромагнитного преобразователя установленного на фольге НП-50 от числа колебательных циклов ее нагружения

Из рис. 7 видно, что частота LRC-генератора совмещенного с фольгой растет с увеличением числа циклов в начале медленно, а затем резко отражая убыль магнитной проницаемости и рост электросопротивления фольги в процессе усталостных изменений в ней и контролируемом элементе конструкции.

\section{4. Заключение}

Исследованы закономерности изменения магнитных параметров ферромагнитных сплавов при их циклической деформации в упругой области.

Показано, что электромагнитные свойства ферромагнитных фольг изготовленных из никеля и его сплавов толщиной 20-40 мкм чувствительны к усталостному воздействию, и могут быть использованы для создания беспроводных датчиков - индикаторов усталостного разрушения элементов конструкций.

Предложено использовать разнотипные ферромагнитные материалы средней магнитной жесткости (например, 30X13 ,30К4МВИ) для разработки и изготовления запоминающих беспроводных датчиков силы (деформации) в виде фольги или проволоки.

\section{Литература}

1. Терентьев В. Ф., Кораблева С. А. Усталость металлов. - М. : Наука, 2015. - 479 с.

2. Nesterenko B. G. Development of regulatory requirements for fatigue and survivability of civilian transport aircraft // Journal of Machinery Manufacture and Reliability. - 2010, no. 6. P. 117-126. - DOI: 10.3103/S1052618810060154.

3. Application of integral-type deformation pickups for evaluating the fatigue damage of carbon composites / S. V. Panin, M. V. Burkov, P. S. Lyubutin, Yu. A. Altukhov, S. A. Khizhnyak // Russian Journal of Nondestructive Testing. - 2014. - Vol. 50, no. 5. P. 288-298. - DOI: 10.1134/S1061830914050052.

4. Сызранцев В. Н., Голофаст С. Л. Измерение циклических деформаций и прогнозирование долговечности деталей по показаниям датчиков деформации интегрального типа. - Новосибирск : Наука, 2004. - 206 с.

5. Копнов В. А., Котельников А. П. Прогнозирование ресурса металлоконструкций транспортных машин датчиками деформаций интегрального типа // Известия высших учебных заведений. Горный журнал. - № 3. - С. 76-82. 
6. Котельников А. П. Применение пленочных датчиков деформаций интегрального типа в диагностике напряженно- деформированного состояния транспортных металлоконструкций // Транспорт Урала. - 2006. - № 3 (10). - С. 57-61.

7. Титоренко К. В., Дудко А. В. Исследование усталости металлов с помощью тензодатчиков // Научный поиск. Теория и практика. Альманах : сборник. - Уфа, 2017. - С. 66-69.

8. Контроль усталости металла коэрцитиметрическим методом как объективная первооснова диагностики оборудования и конструкций / Б. Е. Попов, Г. Я. Безлюдько, Е. И. Елкина, Р. Н. Соломаха // В мире неразрушающего контроля. - 2009. - № 2 (44). C. $28-32$.

9. Дмитриев В. Ф. Беспроводной датчик деформации на поверхностных акустических волнах // Вопросы радиоэлектроники. - 2012. - Т. 2, № 1. - С. 153-162.

10. Исследование величины деформации, напряжений и собственных частотных колебаний звездного датчика при эквивалентном инерционном нагружении / Р. В. Федорцев, Е. Ю. Рогожинский, К. В. Баркин, Д. В. Черенко // Приборы и методы измерений. - 2011, № 2 (3). - С. 92-98.

11. Баранников В. А., Николаева Е. А., Касаткина С. Н. Простой электромагнитный датчик мгновенных деформаций // Заводская лаборатория. Диагностика материалов. 2007. - Т. 73, № 3. - С. 66-68.

12. Новиков В. Ф., Бахарев М. С. Магнитная диагностика механических напряжений в ферромагнетиках. - Тюмень : Вектор Бук, 2001. - 220 с.

13. Magnetoelastic phenomena in residually magnetized cobalt steel / V. F. Novikov, D. F. Neradovsky, B. V. Fedorov, A. V. Strokova // Russian Journal of Nondestructive Testing. 2017. - Vol. 53, iss. 3. - P 198-203. - DOI: 10.1134/S1061830917030068.

14. Ленточный беспроводной датчик деформации / В. Ф. Новиков, К. С. Падерин, К. Р. Муратов, М. С. Бахарев, Е. В. Рогалева // Датчики и системы. - 2011. - № 9. - С. 47-49.

15. Новиков В. Ф, Бахарев М. С, Яценко Т. А. К природе пьезомагнитного эффекта остаточно намагниченного состояния магнетика // Известия ВУЗов. Нефть и газ. - 1998. № 4. - C. 96-102.

16. Electromagnetic Witness Transducers of Pre-Fracture of Structures / V. F. Novikov, N. A. Drozdov, S. M. Kulak, K. R. Muratov, D. F. Neradovskii // Russian Journal of Nondestructive Testing. - 2019. - Vol. 55, no. 8. - P. 603-609. - DOI: 10.1134/S1061830919080096.

17. Дроздов Н. А. Электромагнитные преобразователи - свидетели предразрушения конструкции // Новые технологии- нефтегазовому району : материалы Всероссийской с международным участием научно-практической конференции студентов, аспирантов и молодых ученых. - 2015. - С. 154-157.

18. Федосенко Ю. К., Шкатов П. Н., Ефимов А. Г. Вихретоковый контроль. - М. : Изд-во Спектр, 2011. - 223 с. 